\title{
Assessment of Some Gaseous Emissions in Traffic Areas in Makurdi Metropolis, Benue State, Nigeria
}

\author{
Joseph A. Ameh*, Terrumun A. Tor-Anyiin, Ishaq S. Eneji \\ Department of Chemistry, University of Agriculture, Makurdi, Nigeria \\ Email: *amehjoe96@yahoo.com
}

Received 15 November 2014; accepted 16 November 2015; published 19 November 2015

Copyright (C) 2015 by authors and Scientific Research Publishing Inc.

This work is licensed under the Creative Commons Attribution International License (CC BY). http://creativecommons.org/licenses/by/4.0/

c) (i) Open Access

\section{Abstract}

The level of gaseous emissions ( $\mathrm{CO}, \mathrm{NO}_{2}$ and $\left.\mathrm{SO}_{2}\right)$ at four strategic places in Makurdi metropolitan area of Benue State was determined using handheld TO Crowcon Gasman gas meters for a period of one month, during peak periods of traffic flow at the selected locations within the city. The level of emission recorded at the major road junctions in Makurdi showed CO with highest concentration $(0.57-10.2 \mathrm{ppm})$, followed by $\mathrm{NO}_{2}(0.01-0.11 \mathrm{ppm})$ and $\mathrm{SO}_{2}(0.00-0.1 \mathrm{ppm})$ in all the sampled sites. This showed a concentration pattern of SS1 > SS2 > SS3 > SS4 in all the sampling stations. The results established that the emission levels in metropolis especially in the afternoon were slightly higher than the Nigerian air quality standard accepted safe limits of 10 ppm for atmospheric $\mathrm{CO}, 0.04-0.06 \mathrm{ppm}$ for $\mathrm{NO}_{2}$ and $0.1 \mathrm{ppm}$ for $\mathrm{SO}_{2}$, respectively. These will have adverse health effects and may contribute to climate change, in the long term, if unmitigated.

\section{Keywords}

Carbon (II) Oxide, Nitrogen (IV) Oxide; Sulphur (IV) Oxide, Environmental Pollution, Health Effects

\section{Introduction}

Air pollution has long been recognized as the most fatal form of pollution due to increasing pollution levels as a result of urbanization and growth. This is a source of major concern to both modern and fast growing societies in the world to which Benue State cannot be an exception.

Air pollution can be caused by natural or man-made activities and one of such activities is vehicular emission, which derives their energy from the combustion of fossil fuels. In the process of combustion, vehicles emit into

*Corresponding author.

How to cite this paper: Ameh, J.A., Tor-Anyiin, T.A. and Eneji, I.S. (2015) Assessment of Some Gaseous Emissions in Traffic Areas in Makurdi Metropolis, Benue State, Nigeria. Open Journal of Air Pollution, 4, 175-183. 
the environment exhaust gases, which create serious environmental and health concerns. These emissions contain carbon monoxide (CO), oxides of sulphur (SOx), oxides of nitrogen (NOx), Ozone $\left(\mathrm{O}_{3}\right)$, hydrocarbons and particulate matter. Some of these gases are called Green House Gases (GHGs) [1]. Adverse effects of air pollution on human may be divided into two classes: acute and chronic effects. Acute effects manifest themselves immediately upon short term exposure to air pollutants at high concentrations, and chronic effects become evident only after continuous exposure to low levels of air pollution [2]. The effects of gaseous pollutants on the respiratory system depend on the concentration, period of exposure, and the solubility. Highly soluble gases such as sulphur dioxide are absorbed in the upper parts of the respiratory system whereas relatively insoluble gases like $\mathrm{CO}, \mathrm{NO}_{2}$ and ozone penetrate deep and reach the aveoli of the lungs. Some of the adverse effects of these pollutants include pulmonary edema, emphysema, and prevention of oxygen transfer to blood [3]-[4]. The major sources of air pollution are from industrial and transportation activities. On the empirical balance, transportation is identified as a highly significant culprit accounting for well over $50 \%$ to $80 \%$ of the total air pollutants in developing countries [5]-[7]. However, this situation is alarming and is predicated on the poor economic disposition of developing countries, poor vehicle maintenance culture and importation of old vehicles, which culminates in an automobile fleet dominated by a class of vehicles known as "super emitters" with high emission of harmful pollutants [8]. The increase in this traffic-related pollution is not based on the above factors only, but also on low quality fuel which may be due to the increase in illegal refineries in Nigeria, poor traffic regulation and lack of air quality implementation force among others [9].

The impact and complexity of traffic-related air pollution in Nigeria today, alongside concurrent emissions from industrial and domestic sources therefore necessitates a new approach to the mitigation and management of air pollution. An assessment of the potential for increased vehicular pollution requires some basic information relating to traffic volume and the intensity of pollutant emissions on road corridors [10]. The aim of this work was to determine the emissions level of $\mathrm{CO}, \mathrm{NO}_{2}$ and $\mathrm{SO}_{2}$, compare the emissions level with Nigerian ambient air quality thereby determining the influence factors of pollution in Makurdi metropolitan area of Benue State.

\section{Materials and Methods}

Makurdi is the capital city of Benue State. The city is located along the Benue River bank on latitude 7.44N and longitude 8.32E situated in a valley $100 \mathrm{~m}$ above sea level. Makurdi can be said to be predominantly a civil service and commercial city as most of the administrative offices are situated in the city and as such most of the populace spend their time outdoors. Through careful observations, sampling sites or stations in the metropolis were identified prior to the dates of field work; the coordinates of the sites were obtained using the Global Positioning System. Busy roads in the metropolis were considered due to high traffic volume always experienced on these roads and the location of commercial activities along such roads. Four sampling sites were considered: Wurukum round-about (SS1), High Level round-about (SS2) and Wadata market Junction (SS3) in Makurdi (See Figure 1). Slow movement of vehicles along these roads was a considerable factor in the collection of air samples so as to determine the concentration of pollutants being inhaled by pedestrians and residents of the vicinity. A farm site in the University of Agriculture Makurdi, was used as control site (SS4, where there are no vehicular movements or commercial activities going on).

The raw data obtained at each site was recorded, accordingly for morning, afternoon and evening. Mean values were calculated for repeated measurement to obtain a representative discrete value; statistical analysis of the data was carried out using statistical software programme (SPSS version 16.0). To start measuring the gases (CO, $\mathrm{NO}_{2}$ and $\mathrm{SO}_{2}$ ), the switch is first turned to TEST position. Red LED with flash, sounder will operate, display will indicate battery condition $(100=$ fully charged). After which the switch is turned to Gas position. Unit is then in normal operation. The Green LED will flash and operational sounder will operate once every three seconds to confirm normal operation. The specification for gas and range for $\mathrm{CO}$ gas meter is $0-500 \mathrm{ppm}, \mathrm{SO}_{2}$ gas meter is $0-10 \mathrm{ppm}$ and $\mathrm{NO}_{2}$ gas meter is $0-10 \mathrm{ppm}$ respectively. While the temperature range is $-10^{\circ} \mathrm{C}$ to $+50^{\circ} \mathrm{C}$ and humidity range is $0 \%-90 \% \mathrm{RH}$, non-condensing.

Sample Collection and quantification: The measurement of the concentration of the toxic gases $\left(\mathrm{CO}, \mathrm{NO}_{2}\right.$ and $\mathrm{SO}_{2}$ ) over time (3 minutes interval) for $1 \mathrm{hr} 30$ minutes were made during different phases of traffic (Morning -7:30 am to 9:00 am, Afternoon-12 pm to 1:30 pm and Evening -4:00 pm to 5:30 pm) within a week for each site. The parameters were measured simultaneously using the different meters and the reading was taken $2.0 \mathrm{~m}$ away from the edge of the main road. 


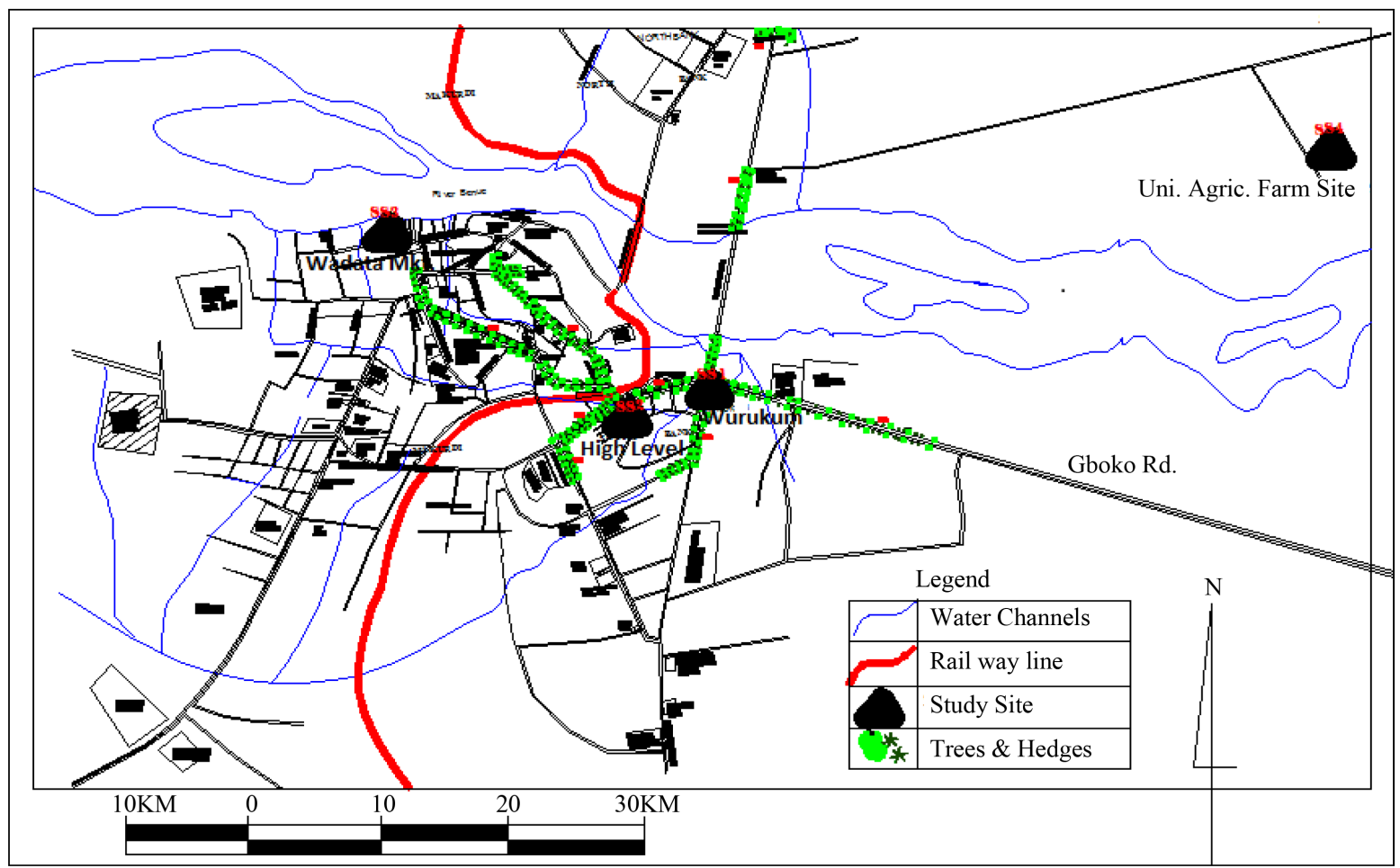

MAP OF MAKURDI Showing Study Sites

Source: Field Survey, 2014.

Figure 1. Map of Makurdi showing study sites.

\section{Results}

The mean of the daily concentration of carbon monoxide (CO), nitrogen dioxide $\left(\mathrm{NO}_{2}\right)$ and sulphur dioxide $\left(\mathrm{SO}_{2}\right)$ obtained at Wurukum round-about, High-level round-about, Wadata Market junction and University of Agriculture Makurdi is shown in a bar chart plot of concentrations (ppm) with time (min) at each study site from morning to evening as shown in Figures 2-5. The instrument for measuring the emission was taken from one site to another for measurement in June, 2013.

\section{Discussion}

The experimental data obtained in this research work for gaseous emission were calculated into discrete mean. The data were obtained from four sampling sites (Wurukum round-about (SS1), High Level round-about (SS2), Wadata Market junction (SS3) and University of Agriculture Makurdi farm site (SS4). The information was plotted into graphs for different sampling periods (morning, afternoon and evening), respectively as shown in Figures 2-5. Comparatively, CO showed highest concentration (ppm) within a range of (0.57 - 10.17), followed by $\mathrm{NO}_{2}(0.01-0.11)$ and $\mathrm{SO}_{2}(0.00-0.10)$ in all the sampled sites. The mean $( \pm \mathrm{SD})$ concentrations $(\mathrm{ppm})$ of the gases obtained in the morning afternoon and evening were; SS1: Morning, CO-8.73 $\pm 4.17, \mathrm{NO}_{2}-0.11 \pm 0.03$ and $\mathrm{SO}_{2}-0.01 \pm 0.03$; Afternoon, CO-10.03 $\pm 4.31, \mathrm{NO}_{2}-0.09 \pm 0.04$ and $\mathrm{SO}_{2}-0.09 \pm 0.03$; Evening, $\mathrm{CO}-8.43 \pm 2.46$, $\mathrm{NO}_{2}-0.11 \pm 0.03$ and $\mathrm{SO}_{2}-0.02 \pm 0.04$ respectively; SS2: Morning, CO-6.23 $\pm 2.86, \mathrm{NO}_{2}-0.11 \pm 0.03$ and $\mathrm{SO}_{2}-0.01 \pm 0.03$; Afternoon, CO- $10.17 \pm 4.45, \mathrm{NO}_{2}-0.00 \pm 0.02$, and $\mathrm{SO}_{2}-0.10 \pm 0.00$; Evening, CO-8.07 \pm 3.65 , $\mathrm{NO}_{2}-0.10 \pm 0.03$ and $\mathrm{SO}_{2}-0.02 \pm 0.04$ respectively; SS3: Morning, CO-5.27 $\pm 3.27, \mathrm{NO}_{2}-0.1 \pm 0.00$ and $\mathrm{SO}_{2}-0.1 \pm$ 0.02; Afternoon, CO-7.07 $\pm 2.46, \mathrm{NO}_{2}-0.06 \pm 0.05$ and $\mathrm{SO}_{2}-0.1 \pm 0.00$; Evening, CO-8.64 $\pm 3.28, \mathrm{NO}_{2}-0.1 \pm$ 0.02 and $\mathrm{SO}_{2}-0.05 \pm 0.06$ respectively, while SS4 has; Morning, $\mathrm{CO}-0.57 \pm 0.09, \mathrm{NO}_{2}-0.01 \pm 0.03$ and $\mathrm{SO}_{2}-0.00 \pm$ 0.02; Afternoon, CO- $1.00 \pm 1.32, \mathrm{NO}_{2}-0.01 \pm 0.03$ and $\mathrm{SO}_{2}-0.00 \pm 0.00$; Evening, CO-1.03 $\pm 1.06, \mathrm{NO}_{2}-0.01 \pm$ 0.03 and $\mathrm{SO}_{2}-0.02 \pm 0.04$ respectively. This showed a concentration pattern of SS1 $>$ SS2 $>$ SS3 $>$ SS4. Though the volume of traffic was high for the three sampled sites (SS 1, SS 2 and SS 3), there was less hold up at SS 3 


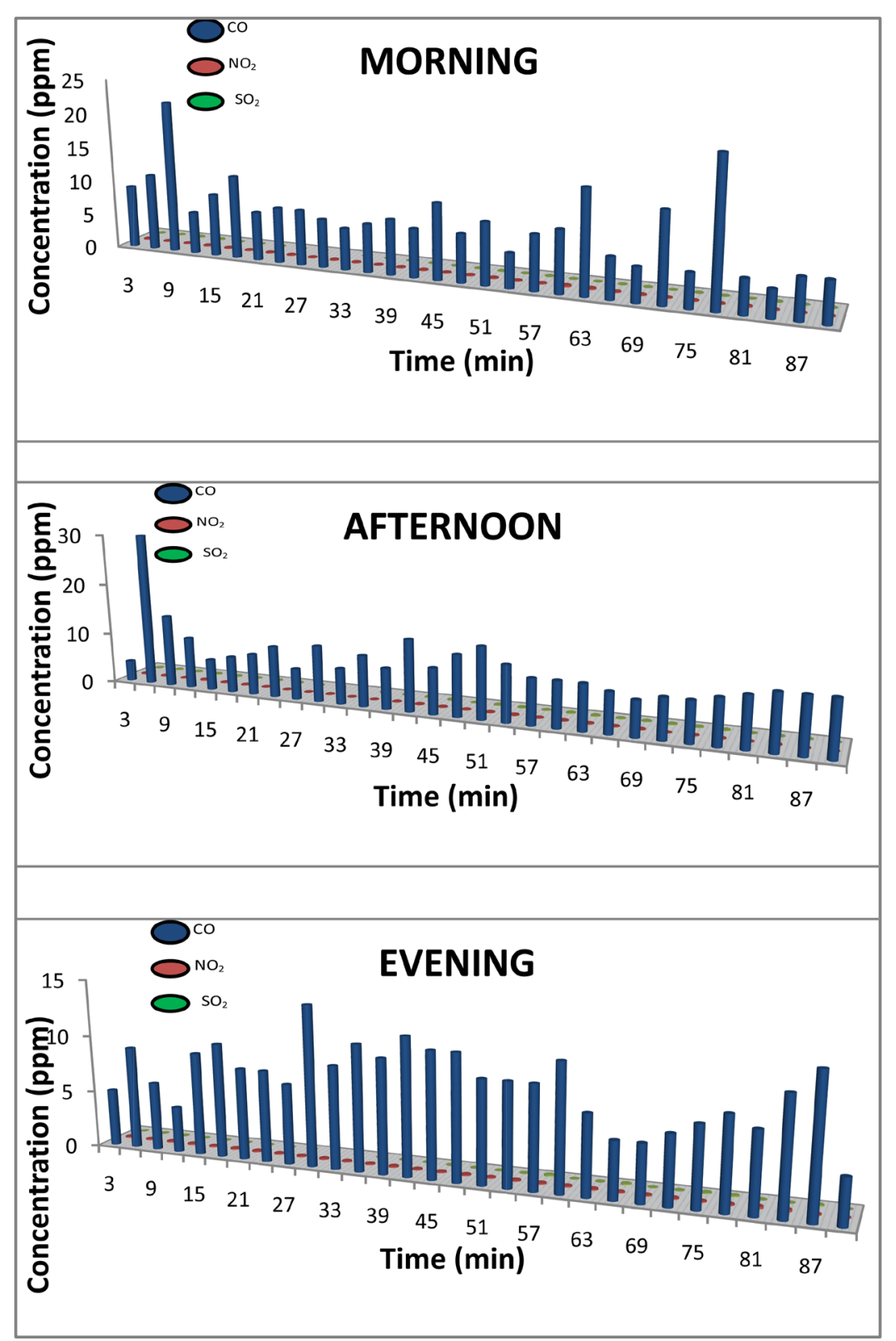

Figure 2. Plot of mean concentrations (ppm) of gases emitted at Wurukum round-about (SS1).

which may be because the sampling was done during working days and as a result, vehicular traffic was low as many persons were rather driving to offices and schools. Movement towards the market (SS3) was less as such the toxic gases may not accumulate, but are quickly dispersed into the atmosphere. However, there was a rise in concentration of $\mathrm{CO}$ in this site in the evening which clearly showed that people usually rush in, to buy things after work, thereby increasing vehicular volume (traffic jam) and human congestion at this time of the day at SS3 [11].

Comparison of CO between sites shows that CO concentration was higher at Wurukum Roundabout in the morning followed by High Level Roundabout, Wadata Market Junction and University of Agriculture farm site respectively. While in the afternoon, High Level Roundabout recorded the highest concentration followed by Wurukum Roundabout, Wadata Market junction and University of Agriculture Farm sites. And lastly in the evening, Wadata Market junction recorded highest concentration followed by Wurukum Roundabout, High 

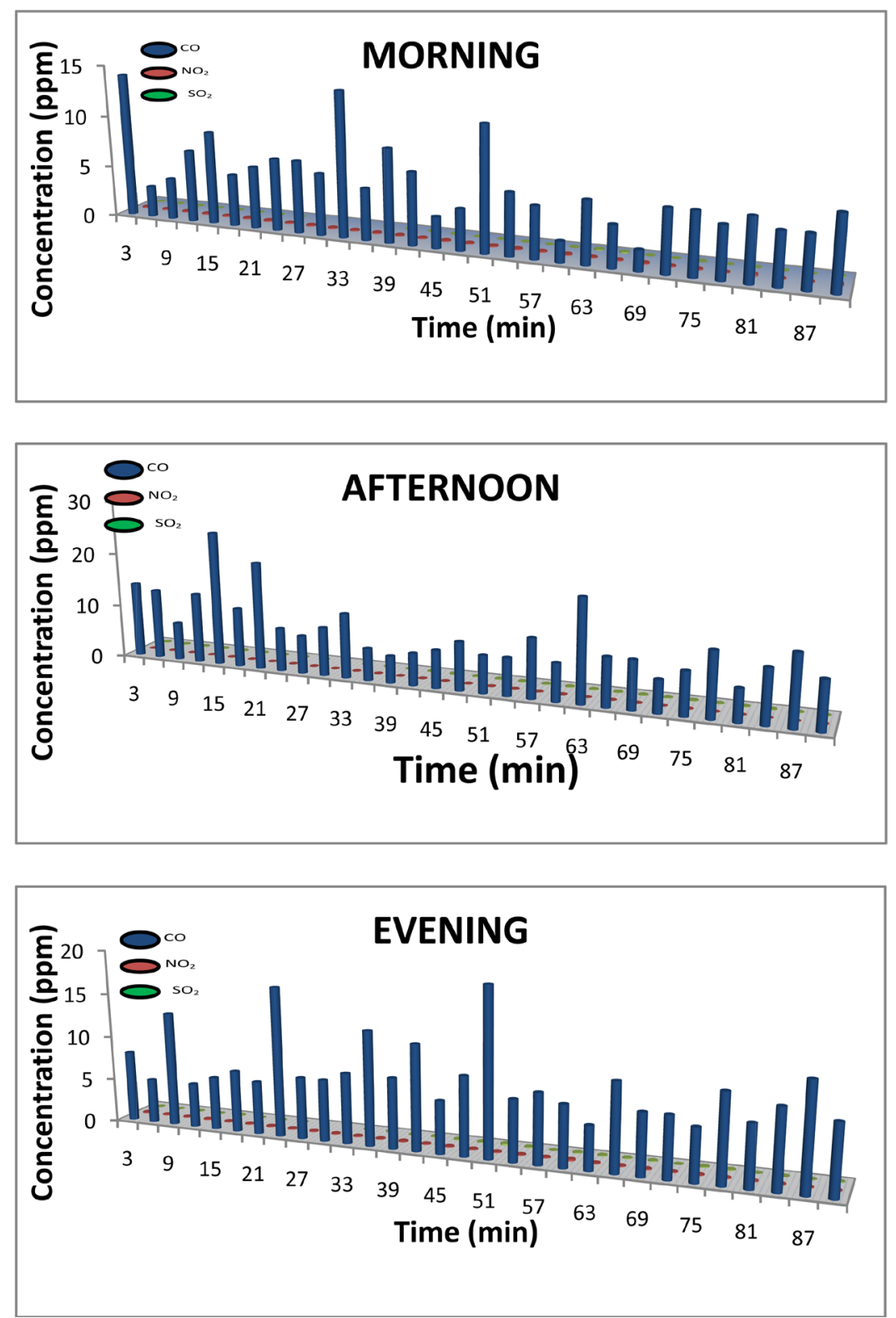

Figure 3. Plot of mean concentrations (ppm) of gases emitted at high-level round-about (SS2).

Level Roundabout and University of Agriculture farm site.

Comparison of $\mathrm{NO}_{2}$ concentrations between sites shows that Wurukum Roundabout recorded highest in the morning, followed by High Level Roundabout, Wadata Market Junction and University of Agriculture farmsite. While in the afternoon, Wurukum Roundabout recorded the highest followed by Wadata Market Junction, University of Agriculture farm site and High Level Roundabout. And lastly, in the evening, Wurukum Roundabout recorded the highest followed by High Level Roundabout, Wadata Market Junction and University of Agriculture farm site.

Comparison of $\mathrm{SO}_{2}$ concentrationsbetween sites shows that Wadata Market Junction recorded highest in the morning, followed by Wurukum Roundabout, High Level Roundabout and University of Agriculture farm site. While in the afternoon, Wadata Market Junction recorded the highest followed by High Level Roundabout and University of Agriculture farm site. And lastly, in the evening, Wadata Market Junction recorded the highest followed by Wurukum Roundabout, High Level Roundabout and University of Agriculture farm site, respectively. 


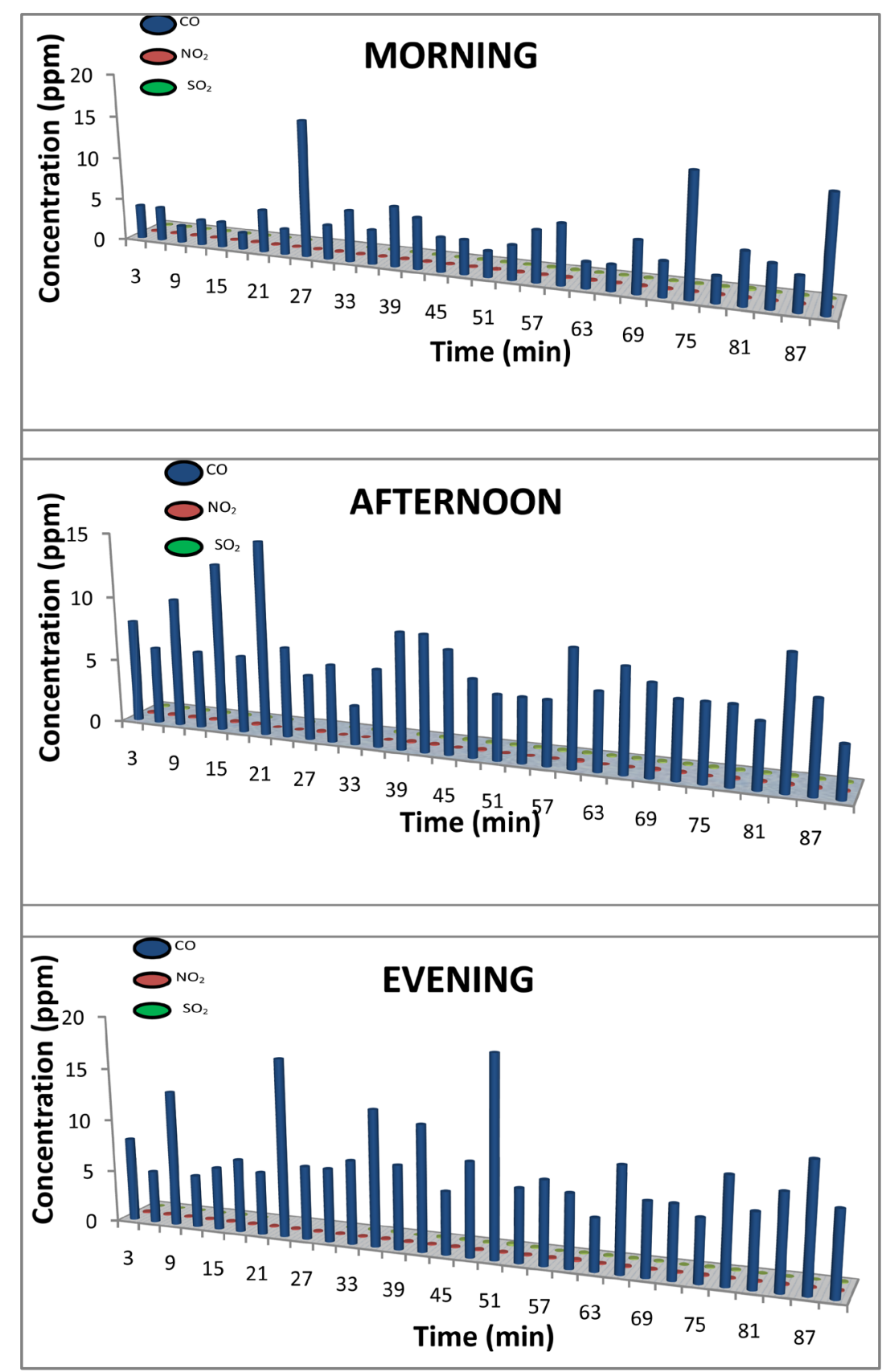

Figure 4. Plot of mean concentrations (ppm) of gases emitted at Wadata Market Junction (SS3).

The total average concentration of Carbon monoxide (CO) measured at SS1, SS2, SS3 and SS4, for the four study areas was below the minimum standard (10 ppm) stipulated by the Federal Environmental Protection Agency, now known as National Environmental Standards and Regulations Enforcement Agency (NESREA). However, the level of CO emission for SS1 and SS2 for afternoon was slightly above the standard. This high concentration of CO at SS1 and SS2 may be due to increased transport activities from both vehicles and motor cycles. The result revealed that the higher the number of vehicles, the higher the emission problems to the environment. Omofonmwan and Osa-Edoh [12], supported this finding when they stated that in Nigeria, several rural towns that had in the past enjoyed fresh and dry air are currently experiencing air pollution problems. On the empirical balance, transportation is identified as a highly significant culprit, accounting for well over $50 \%$ to $80 \%$ 

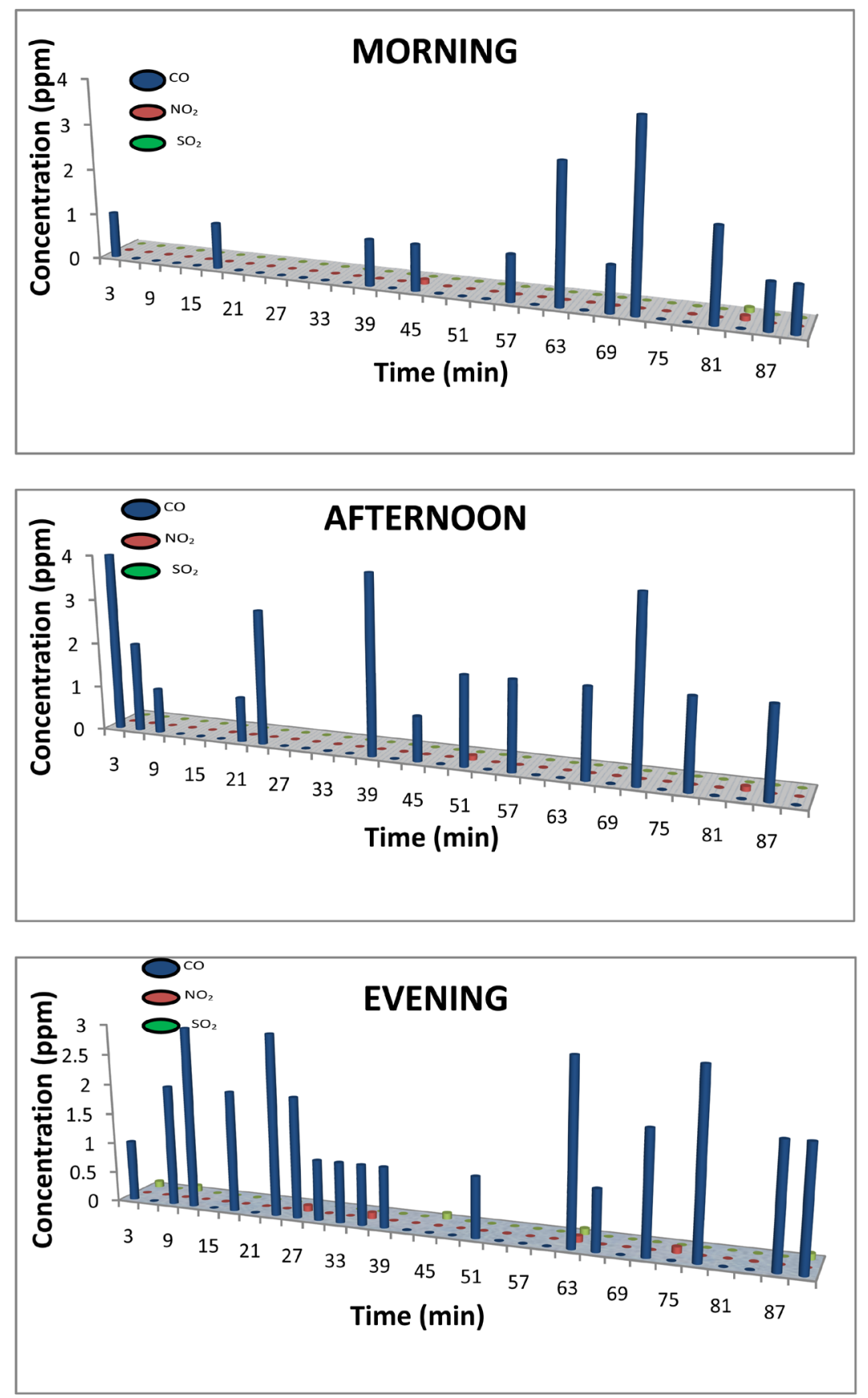

Figure 5. Plot of mean concentration (ppm) of gases emitted at University of Agriculture Makurdi, farm site.

of the total air pollutants in developing countries [5]-[7]. This is an indication that vehicular emissions are a major source of environmental problem and must be controlled if acceptable air quality is to be assured. In addition, there are numerous health problems associated with high concentration of these emissions. The high concentration of CO observed in this study has also been confirmed by WHO [13], which reported that concentrations of CO were highest at near street intersections, in congested traffic, near exhaust gases from internal combustion engines and from industrial sources, and in poorly ventilated areas such as parking garages and tunnels.

The quantity of $\mathrm{NO}_{2}$ measured at SS1, SS2, SS3 and SS4 out of the four study areas was higher than the 0.04 0.06 ppm (minimum standard stipulated by the National Environmental Standards and Regulations Enforcement 
Agency) while SS4 fell below the standard. However, $\mathrm{NO}_{2}$ concentration was very low in the afternoon and this may be due to photochemical reaction taking place at that time of the day (VanLoon and Duffy [14]). WHO [13], stated that road traffic is responsible for half of the total $\mathrm{NO}_{2}$ emissions. Goyal [6], also stated the fact that automobile emissions contribute about $50 \%-80 \%$ of $\mathrm{NO}_{2}$ concentration in developing countries. This situation is alarming and is due to poor economic development of developing countries. Long term effects of $\mathrm{NO}_{2}$ exposure from automobile emission is that $\mathrm{NO}_{2}$ undergoes photochemical reactions to produce ozone and this result to respiratory irritant which is known to exacerbate asthma. The quantity of $\mathrm{SO}_{2}$ measured at SS1, SS2 and SS3 is higher than the $0.01 \mathrm{ppm}$ standard stipulated by the National Environmental Standards and Regulations Enforcement Agency except at SS4 which was very close to the standard. A similar study carried out in Lagos and the results obtained for $\mathrm{SO}_{2}$ per minute were found to be higher than NESREA limits Koku and Osuntogun [15]. This was supported by Erica [16], who observed that the hourly $\mathrm{SO}_{2}$ concentration in Abuja exceeded the Nigerian ambient air quality standard during all readings and in all locations. This study showed increasing trend and thus, posing a potential health effects to the population. In addition low quality of fuel, lack of traffic regulation and infrastructure, and lack of air quality enforcement contribute to the high levels of automobile emissions Sikirulahi and Salami [17]. The findings indicate that the contributions of automobile emissions to the environmental problems in Benue State are obvious. Increased $\mathrm{NO}_{2}$ and $\mathrm{SO}_{2}$ emissions from motor cycles and vehicles will have effect on driving performance. Akio [18] stated that many motor cycles use rich combustion, in which fuel is burned in excess in order to achieve optimum driving performance with minimum displacement. Contrarily, petrol engine lacks oxygen sensor control while motor cycles have no readjustment mechanism, and the oxygen excess is not corrected which may have contributed to an increased $\mathrm{NO}_{2}$ and $\mathrm{SO}_{2}$ emissions as indicated in the result from SS3, which gave the highest mean value of $\mathrm{SO}_{2}$. SS3 is a Market junction close to water body and the major source of transportation is by water and road. The market is always busy weekends but less busy on working days. Refuse burning of polythene material could also be responsible for the high $\mathrm{SO}_{2}$ concentration.

\section{Conclusion}

The contribution of traffic related air pollution to the air quality in locations of different traffic density in Makurdi was apparent, especially in the high traffic areas. The concentration of pollutants in different traffic density areas varied significantly in the different sites. Results of this study showed that transport-related pollution in Makurdi metropolis is significant and need to be monitored. It is likely that air quality will deteriorate as the city continues to grow which will result in possible severe health consequences. The overall comparison of data for different sections showed fluctuation in the concentrations of the pollutants depending on the volume of traffic, vehicular type and pollution level as shown in the graphs above. Therefore, Benue State environmental Protection Agency should thus recognize air quality management as a priority and work to prevent further environmental degradation by adopting effective policy, such as inspecting commercial vehicles in the metropolis. This also shows that diseases and effects such as runny nose, chest pain, coughing, eye irritation and sore throat, cardiovascular and pulmonary disease, lungs asthma, et cetera are likely to be prevalent in the metropolis.

\section{Acknowledgements}

We wish to acknowledge Peter Onuwa, Ofuegbu Obinna and Blessing Ogoh for their support during sampling and compilation of data and also staff of Benue State Environmental and Sanitation Board.

\section{References}

[1] Abogu, D. (2014) Pushing towards Vehicle Emission Testing in Nigeria. Hits: 473. www.dailytrust.com.mg/daily/index..php/environment/15482-pushing-towards-vehicle-emission-testing-in-nigeria

[2] Rao, C.S. (2006) Environmental Pollution Control Engineering. Reprint, New Age International Ltd., Onitsha, Anambra State, Nigeria, 30-71.

[3] Ababio, O.Y. (2000) New School Chemistry, New Edition Textbook: Africana-Feb Publisher Limited, Book House Trust, 1, Africana-Feb Drive, P.M.B 1639, Onisha, Nigeria, 245-254.

[4] Raub, J.A. and Benignus, V.A. (2002) Review: Carbon Monoxide and the Nervous System. Neuroscience and Behavioral, 26, 925-940. http://dx.doi.org/10.1016/S0149-7634(03)00002-2

[5] Fu, L. (2001) Assessment of Vehicle Pollution in China. Journal of the Air and Waste Management, 5, 658-668. 
http://dx.doi.org/10.1080/10473289.2001.10464300

[6] Goyal, S. (2006) Understanding Urban Vehicular Pollution Problem Visa-Vis Ambient Air Qualities Study of Megacity (Delhi, India). Environmental Monitoring and Assessment, 119, 557-569. http://dx.doi.org/10.1007/s10661-005-9043-2

[7] USEPA (1993) Guide to Environmental Issues, Doc. United States Environmental Protection Agency, Washington DC, No 520/B-94-01.

[8] Ibrahim, B.G. (2009) Strategic Approach to Reducing Vehicle Emissions in Nigeria: Role of Fleet Operators. A Lecture Presented at Safety Managers Training Program, FRSC Academy Jos, Nigeria on the 28th August.

[9] Okunola, O.J., Uzairu, A., Gimba, C.E. and Kagbu, J.A. (2012) Assessment of Gaseous Pollutant along High Traffic Roads in Kano Metropolis, Nigeria. International Journal of Environment and Sustainability, 1, 1-15.

[10] Ojo, O.O.S and Awokola, O.S. (2012) Investigation of Air Pollution from Automobiles at Intersections on Some Selected Major Roads in Ogbomosho, South West, Nigeria. IOSR Journal of Mechanical and Civil Engineering, 1, 31-35. http://dx.doi.org/10.9790/1684-0143135

[11] Asheshi O.O (2012) Measurement of Traffic Emission in Lafia Metropolis. Journal of Science and Multidisciplinary Research, 4, 34-46.

[12] Omofonmwan, S.I. and Osa-Edoh, G.I. (2008) The Challenges of Environmental Problems in Nigeria. Journal of Human Ecology, 23, 53-57.

[13] World Health Organization (2000) Air Quality Guidelines 2000 (Chapter on Nitrogen Dioxide). http://www.euro.who.int/document/aiq/71nitrogendioxide.pdf

[14] VanLoon, G.W. and Duffy, S.J. (2000) Environmental Chemistry, a Global Perspective. 1st Edition, Oxford University Press Inc., New York, 25-92, 134-183.

[15] Koku, C.A. and Osuntogun, B.A. (2007) Environmental-Impacts of Road Transportation in Southwestern States of Nigeria. Journal of Applied Sciences, 7, 2536-2360.

[16] Erica, M. (2009) Vehicle Emissions and Health Impacts in Abuja, Nigeria. http://www.envstudies.brown.edu/theses/archive20072008/ericamoenthesis.pdf

[17] Sikirulahi, G.A. and Salami, K.A. (2013) Contributions of CO, $\mathrm{NO}_{2}$ and $\mathrm{SO}_{2}$ from Automobile Emission to Environmental Problems in Niger State, Nigeria. International Journal of Environmental Sciences, 3, 1457-1466.

[18] Akio, M. (2003) Future Policy for Motor Vehicle Emission Reduction (Seventh Report) Central Environment Council, Chukanshin No. 142, 13. 